\title{
Analysis of Transport and Vehicular Crash Cases Using the Online National Electronic Injury Surveillance System (ONEISS) from 2010 to 2019
}

\author{
Jinky Leilanie Lu, MOH, PhD, ${ }^{1}$ Teodoro J. Herbosa, MD² and Sophia Francesca Lu, MOS ${ }^{3}$ \\ ${ }^{1}$ National Institutes of Health, University of the Philippines Manila \\ ${ }^{2}$ Department of Emergency Medicine and Department of Surgery, College of Medicine and Philippine General Hospital, University of the Philippines Manila \\ ${ }^{3}$ School of Labor and Industrial Relations, University of the Philippines Diliman
}

\begin{abstract}
Introduction. Around 1.35 million people die due to road traffic accidents yearly. In the Philippines, there is an increasing trend of mortality and morbidity caused by road crashes.

Objective. The objective of the study is to show the epidemiology of transport and vehicular crash (TVC) cases in the Philippines using the Department of Health (DOH) Online National Electronic Injury Surveillance System (ONEISS) from 2010 to 2019.

Methods. We used data from ONEISS, a web-based system to electronically capture injury-related data from health facilities, store data in a centralized and secure location, process and consolidate data, and transform this data into meaningful information. For Transport and Vehicular Crash cases, risk factors such as drug use, alcohol use, mobile phone use, seatbelt, and helmet use are included. There are also data on vehicle type, place of crash, and activity. Descriptive and inferential statistics were computed to explore and analyze the ONEISS dataset, particularly the epidemiology of transport and vehicular crashes (TVC).
\end{abstract}

Results. There were a total of 296,760/894,989 (31\%) patients admitted due to transport and vehicular crash (TVC) based on the 10-year data from ONEISS (2010-2019). There was an increasing trend in the number of transport/ vehicular crashes (TVC) during this period, with an average increase of $25.58 \%$ cases per year. Most victims were drivers (45.6\%), males (72.5\%), and from the younger age group (0-30 years old). Fatal crashes were observed to occur from 6:00 pm to 5:00 am while most accidents occurred during leisure activities (32.5\%). The highest reported contributing factor was drunk driving ( $n=25,537$ ). There was observed low compliance on the use of vehicular safety equipment. The most common types of injuries for the TVC victims were abrasions, contusions, burns, and concussions while the vehicle most involved in TVC was the motorcycle. Motorcycle use was found to be associated with worse emergency room (ER) outcomes $(p<.0001)$ and the highest injury types such as multiple injuries, abrasion, avulsion and burn. Alcohol use was also significantly associated with multiple injuries, abrasion, avulsion, burn, open fracture, open wound, and amputation $(p<0.05)$.

Conclusion. The trend of road traffic vehicular crashes affecting mainly the younger population has economic repercussions. Motorcycles are also most involved in crashes, hence, the need for motorcycle safety laws in the country. There is also a need to strengthen current laws and legislation governing road safety and to focus on structuring a systematic post-crash response for both the local government and hospitals throughout the Philippines.

Key Words: traffic and vehicular crashes, traffic, alcoholic intoxication

\section{INTRODUCTION}

Corresponding author: Jinky Leilanie Lu, MOH, PhD

National Institutes of Health

University of the Philippines Manila

623 Pedro Gil Street, Ermita, Manila 1000, Metro Manila

Email: jdlu@up.edu.ph
Road traffic is reported to kill about 1.35 million annually, ${ }^{1}$ higher than the recorded 1.5 million deaths in 2000 , making road traffic accidents the $8^{\text {th }}$ leading cause of deaths worldwide. ${ }^{2}$ Moreover, road traffic injuries have been the leading cause of death for children and populations 
aged 5 to 29 years old. ${ }^{3}$ The most common risk factors for road traffic crashes are human errors such as speeding, driving under influence of alcohol and psychoactive substances, non-use of safety equipment (i.e., helmet, seatbelt, and child restraints), and distracted driving. On the other hand, risk factors that also impact road safety include poor road infrastructure, unsafe vehicles, inadequate post-crash care, and poor implementation of law enforcement of road traffic laws. The most vulnerable group consists of pedestrians, cyclists, and motorcyclists. They take $54 \%$ of all road traffic deaths. ${ }^{3}$ These road traffic accidents pose problems, especially in developing countries. About $93 \%$ of fatalities on roads worldwide come from low-to-middle income countries (LMICs). This is alarming given that about $60 \%$ of vehicles are in LMICs. In general, road traffic accidents cause a 3\% GDP loss yearly. ${ }^{1}$ In the Philippines, the estimated cost of death and injuries in 2014 due to accidents on the road is Php 1.2 billion for medical costs, and Php 26.5 billion for the cost of lost productivity due to illnesses and injuries. ${ }^{4}$

This study aims to provide a profile of transport and vehicular crash (TVC) cases in the Philippines using a 10year data (2011-12019) from the online national electronic injury surveillance system (ONEISS). This can provide a status on road safety in the country and can serve as the basis for policy and program formulation of the government, whether on a local or national level.

\section{MATERIALS AND METHODS}

This is a retrospective study using the Online National Electronic Injury Surveillance System (ONEISS) database of the Department of Health. This web-based system electronically captures injury-related data from health facilities, stores data in a centralized and secure location, processes and consolidates data, and transforms this data into meaningful information. It establishes a 1) standard set of injury-related data elements collected for surveillance, and 2) standards to facilitate the collection, management, transmission, analysis, access, dissemination, and sharing of data. ONEISS was initially implemented in six pilot hospitals, but it has expanded to include more than $80 \%$ of all government and private hospitals and infirmaries in the Philippines. Health facilities with training on ONEISS are required to report injuries managed within their institution. There were $37 \mathrm{DOH}$ hospitals, 98 government hospitals, and 167 private hospitals reporting to the ONEISS in 2015. There has been an average of 304 hospitals reporting to the ONEISS since 2015, however, this number was as low as 72 before 2015 . The year 2016 had the greatest number of hospitals (375) reporting to the surveillance system. The majority of the data in the ONEISS, however, comes from $\mathrm{DOH}$ hospitals (50.5\%), followed by government hospitals (26.2\%) and private hospitals (23.3\%).

We were granted access to the data from 2010 to 2019 in the ONEISS database subject to guidelines approved by the
Department of Health- Single Joint Research Ethics Board (DOH-SJREB).

The ONEISS houses a vast variety of variables. Demographic variables include age, gender, and civil status. There are also data on pre-admission such as attendance in the emergency room (ER) and outpatient department (OPD), first aid management, place of injury (POI), time of injury (TOI), nature of injury (NOI), external cause of injury, and intent. ONEISS also keeps track of patient's severity, ER outcome, inpatient outcome, disposition, and transport details. For transport and vehicular crash cases, risk factors such as drug use, alcohol use, mobile phone use, seatbelt, and helmet use are included. Data is also collected on vehicle type, place of the crash, and activity.

Descriptive and inferential statistics were computed to explore and analyze the ONEISS dataset. Descriptive statistics were presented as graphs, charts, and tables, while inferential statistics were computed using the Chi-square test for association.

\section{RESULTS}

The total number of cases reported in ONEISS was 894,989 from January 2010 to June 2019. The transport/ vehicular crash (TVC) cases accounted for 296,760 (33.1\%). As of $2019,81.5 \%$ of hospitals in the Philippines were trained on the use of ONEISS. The average number of hospitals reporting to the ONEISS was 304 since 2015, but it was as low as 72 before 2015 (Figure 1). There is a dip in this number in 2019 since the available data is only till the second quarter of 2019.

The 10-year data from ONEISS showed an increasing trend in the number of admitted patients due to TVC, with an average increase of $25.58 \%$ per year (Figure 1). The largest portion of transport/vehicular crash data in the ONEISS came from Region IV-A (33,640 cases). This was followed by Region III (28,945 cases), Region XI (27,686 cases), NCR (27,602 cases), and Region VI (26227 cases) (Figure 2).

The majority of the cases $(50.5 \%)$ in the ONEISS came from $\mathrm{DOH}$ hospitals, while $26.2 \%$ came from government hospitals, and 23.3\% from private hospitals. As of 2019 2Q, $81.5 \%$ of hospitals in the Philippines were trained in using ONEISS. Previous years have had much lower cases due to lower participation from hospitals across the country (Table 1).

Most of the cases belong to the 0- to 30-year-old age group. The histogram first peaked for 5-year-olds, while the final peak was for 20 -year-olds. The mean age was 29.42 (SD 16.57) (Figure 3).

A huge majority of TVC patients are males (72.5\%), almost 3 times the number of females. For civil status, the two most common were single (62\%) and married (36\%). Only $1.6 \%$ were reported as widowed and $0.1 \%$ were separated (Table 2). The most common victim types for TVC 


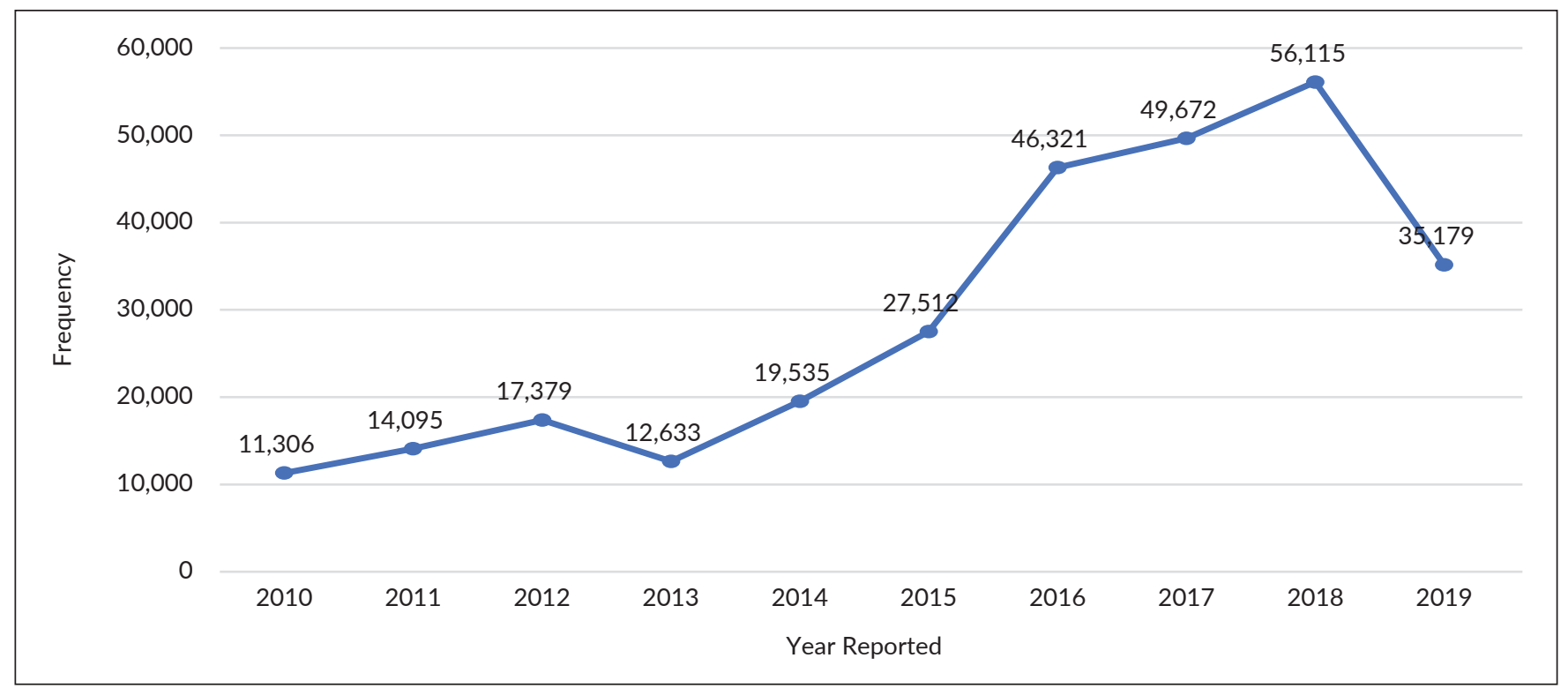

Figure 1. Distribution of ONEISS TVC reported from 2010 to 2019 ( $n=296,760)$.

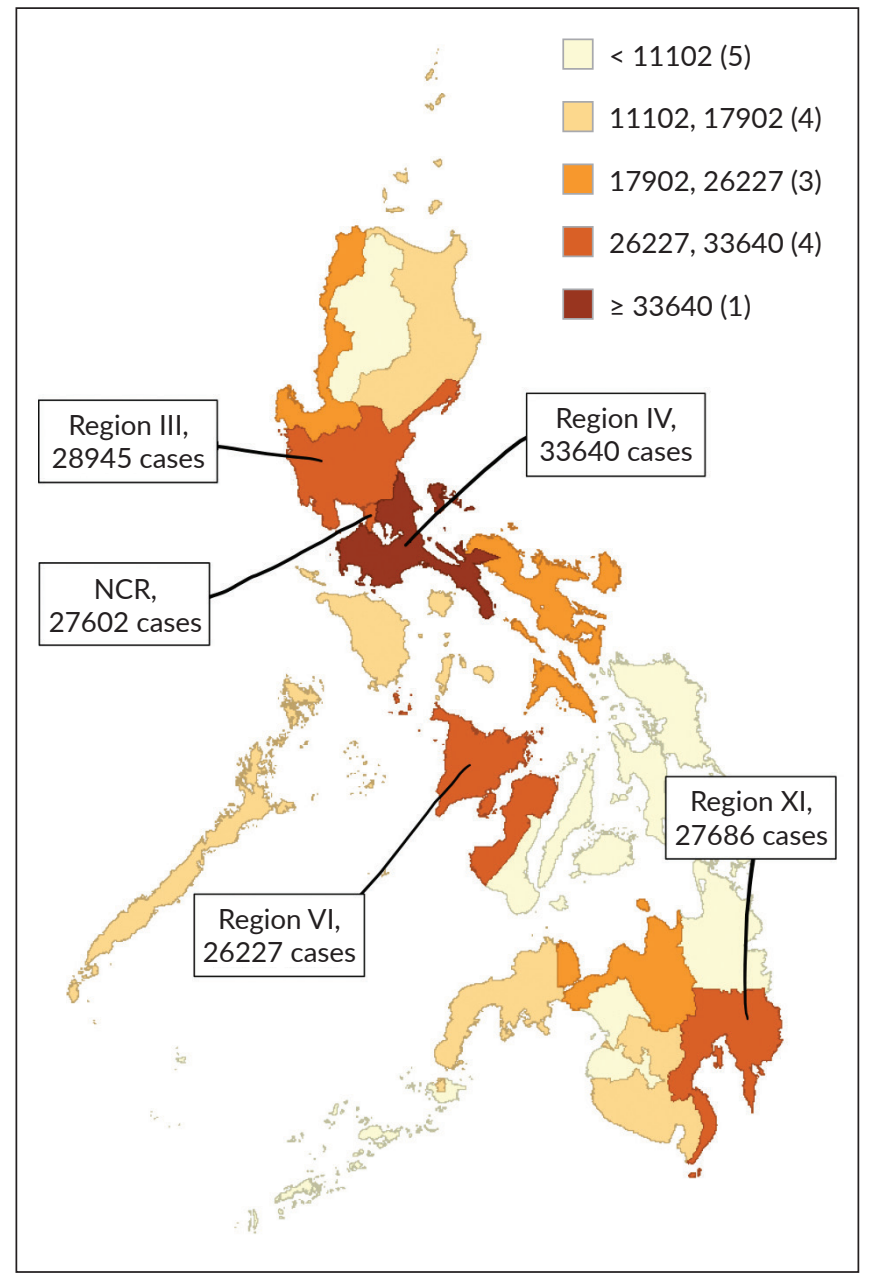

Figure 2. Natural breaks map of transport/vehicular crashes in the Philippines.

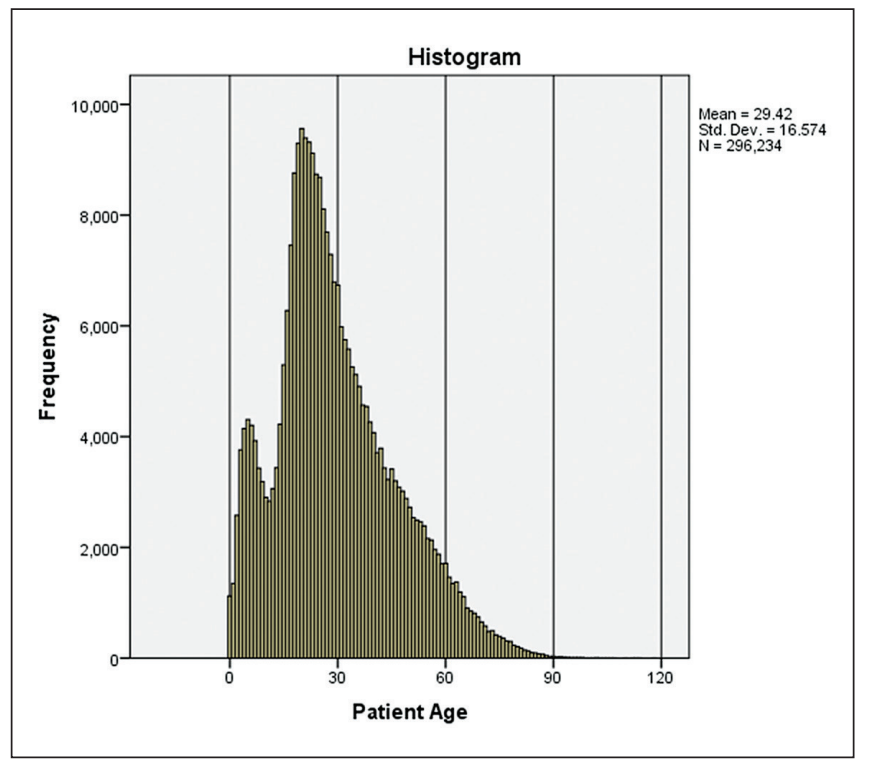

Figure 3. Patient age distribution.

were driver (45.6\%) followed by rear passengers (25.8\%), and pedestrians (13.9\%). There were also $11.6 \%$ unknown victim types (Figure 4$)$.

The most commonly reported activity of TVC patients when involved in a road crash was "leisure" (32.5\%) (Figure 5). Meanwhile, work-related activities are reported to be at $4.9 \%$. The majority $(75.2 \%)$ of the TVC patients were brought to the hospital through a private vehicle. Only $15.8 \%$ were brought by ambulance and the least used vehicle was a public vehicle at $0.3 \%$. Also, $99.7 \%$ of TVC patients were alive when brought to the hospital. Data from the ONEISS showed that generally, fatal crashes, serious 
Table 1. Distribution of data in ONEISS categorized per hospital $(n=296,760)$

\section{Type of Hospital}

DOH Hospital

Government Hospital

Private Hospital

\section{Frequency (\%)}

\section{Percent (\%)}

149,856

77,881

69,023

26.2

23.3

injuries, and minor injuries happen at night with 6:00 pm as the peak and dips at 5:00 am. Among these alive patients, most were reported to be conscious $(83.7 \%)$ and only $1.5 \%$ were unconscious. Only $0.3 \%$ were declared dead on arrival (Figure 6). For those brought to the hospitals, $86.9 \%$ suffered
Table 2. Distribution of sociodemographic characteristics from ONEISS dataset

\begin{tabular}{lrc}
\multicolumn{1}{c}{ Variable } & Frequency (n) & Percent (\%) \\
Sex & & \\
Female & 74,050 & 27.5 \\
$\quad$ Male & 195,518 & 72.5 \\
\hline Civil status & & \\
$\quad$ Single & 42,610 & 62.0 \\
Married & 24,746 & 36.0 \\
Widowed & 1,081 & 1.6 \\
Live-in & 190 & 0.3 \\
Separated & 102 & 0.1 \\
\hline
\end{tabular}

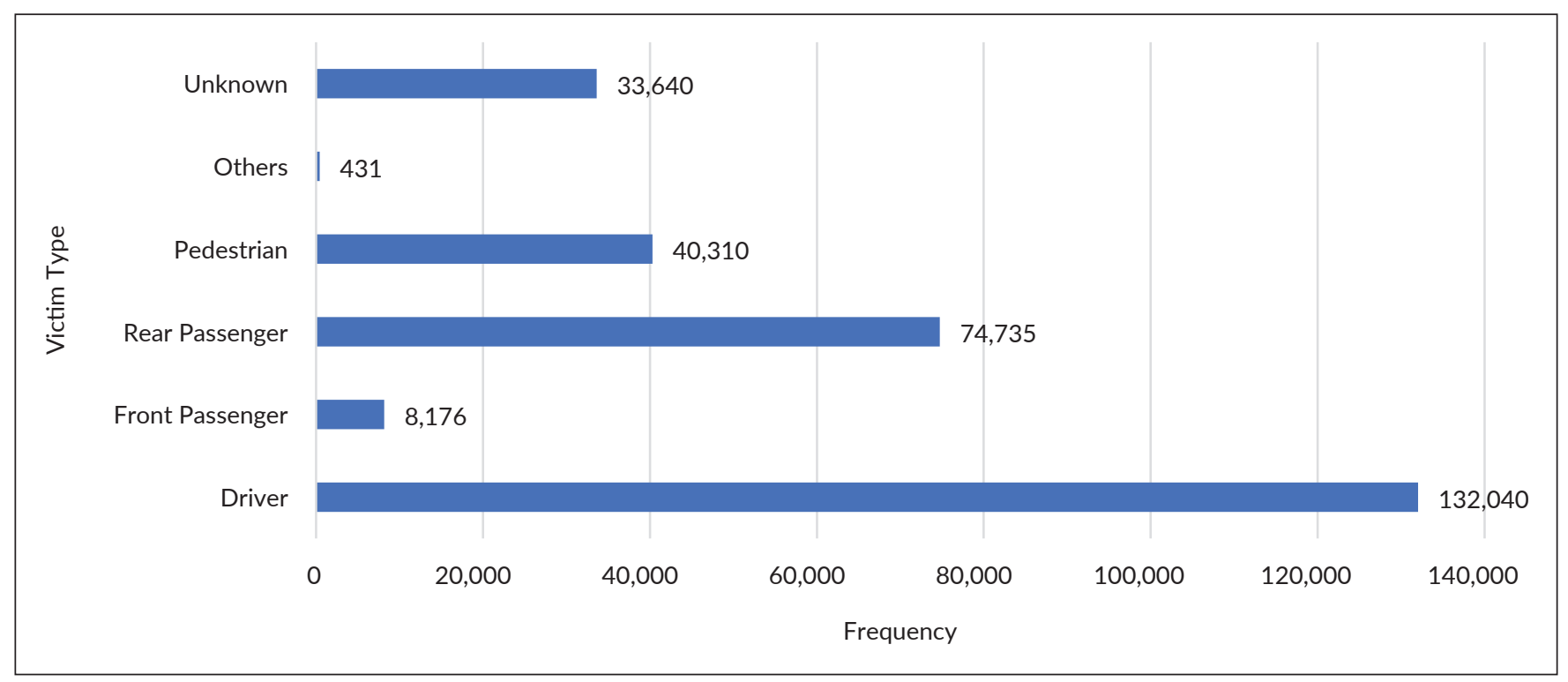

Figure 4. Distribution of victim type from ONEISS dataset $(n=289,342)$.

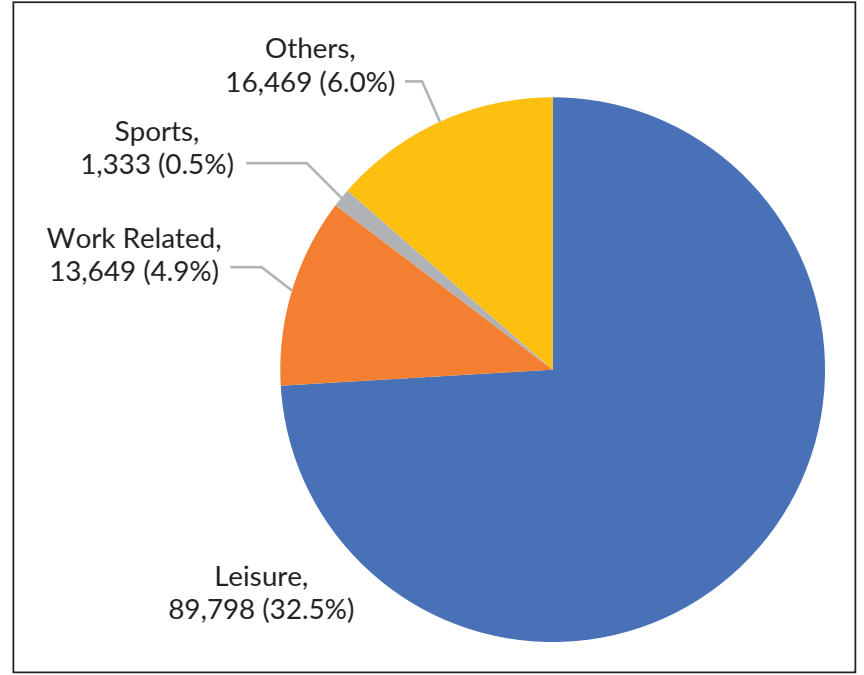

Figure 5. Distribution of activity of TVC patients from ONEISS dataset.

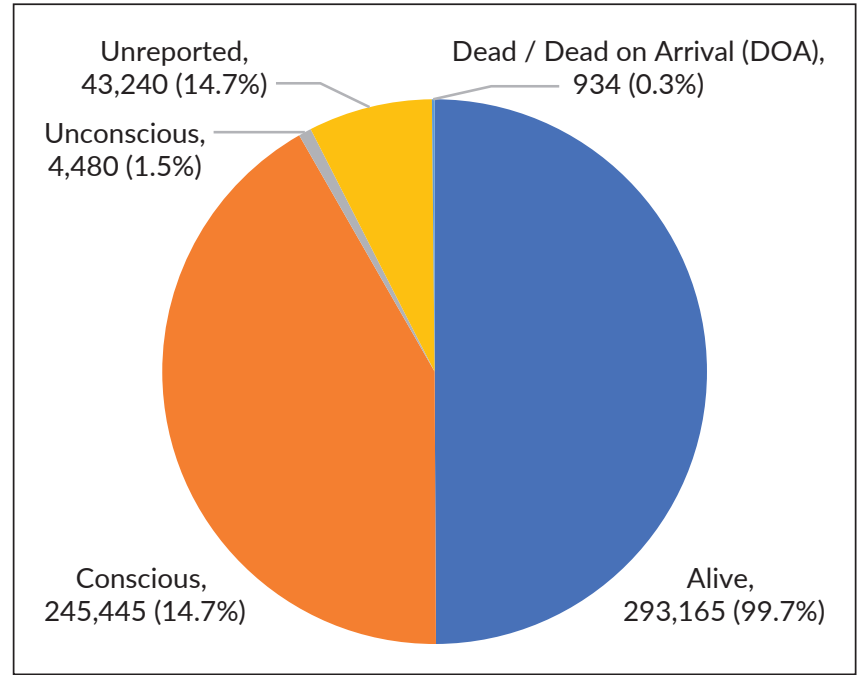

Figure 6. Distribution of status of patient upon arrival at the hospital. 
minor injuries. $1 \%$ have fatal injuries and $0.2 \%$ suffered damage to property. Fatal crashes peaked at 6:00 pm and dipped at 5:00 am. A similar pattern seems to be true for serious injuries and minor injuries (Figure 7).

Motorcycle drivers account for $53 \%$ to $62 \%$ of patients brought to hospitals each year. Pedestrians account for $9 \%$ to $14 \%$ of the cases reported each year (Figure 8 ).

Alcohol is the most commonly reported risk factor contributing to a road crash. Other risk factors included sleep, smoking, use of mobile phones, and drug use (Figure 9).
For the nature of the injury, abrasion was the most common type of injury reported. This is followed by open wound, contusion, and closed fracture. This was observed to be the same case for the years 2010 to 2019 (Figure 10).

The number of TVC patients without an airbag, helmet, car seat, and seatbelt seem to be increasing every year. The most-reported usage of safety gadgets was helmet use. The increase in the number of people not using safety equipment may be attributed to ONEISS having a wider coverage of hospitals throughout the years (Figure 11).

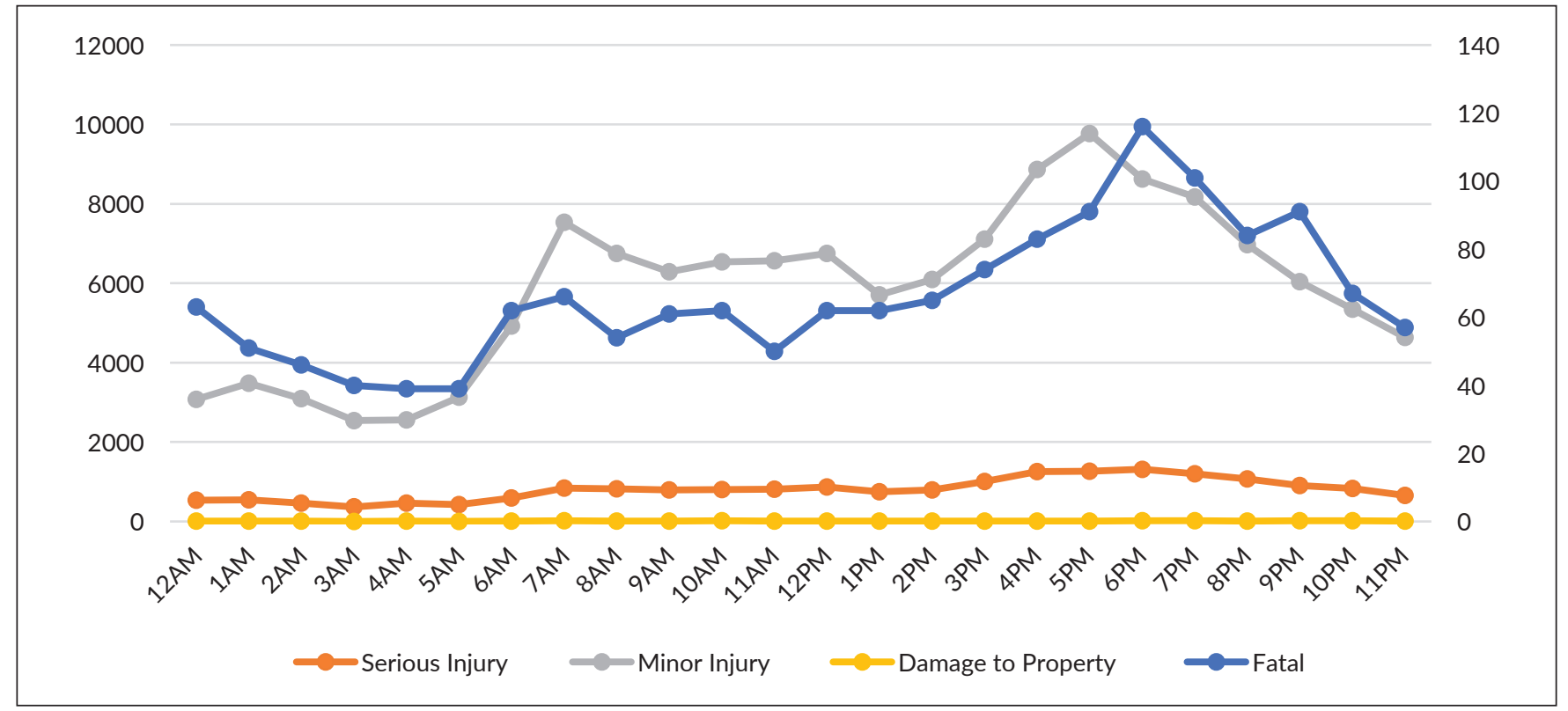

Figure 7. Distribution of injury of TVC patient and time of the crash.

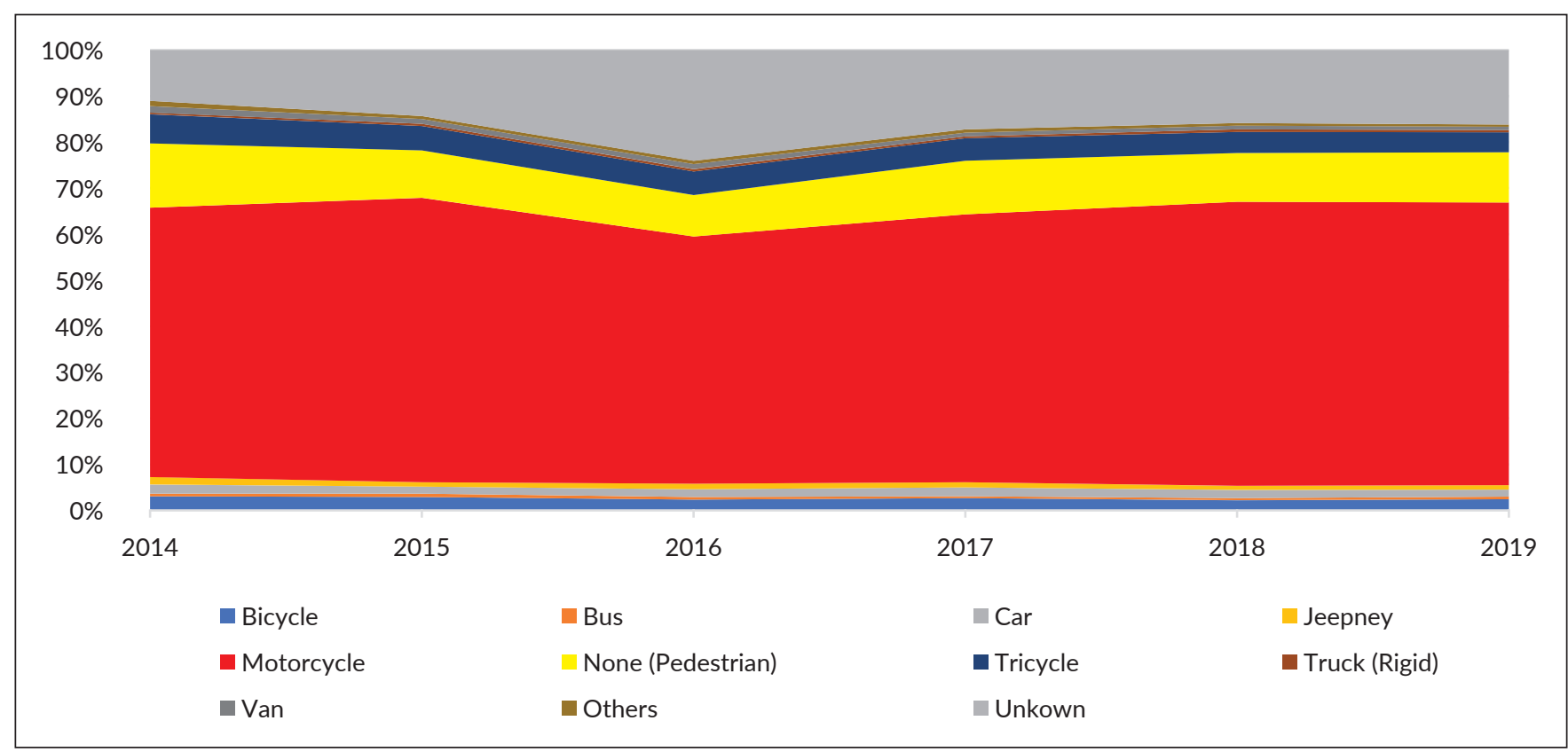

Figure 8. Distribution of type of transportation of TVC patients. 


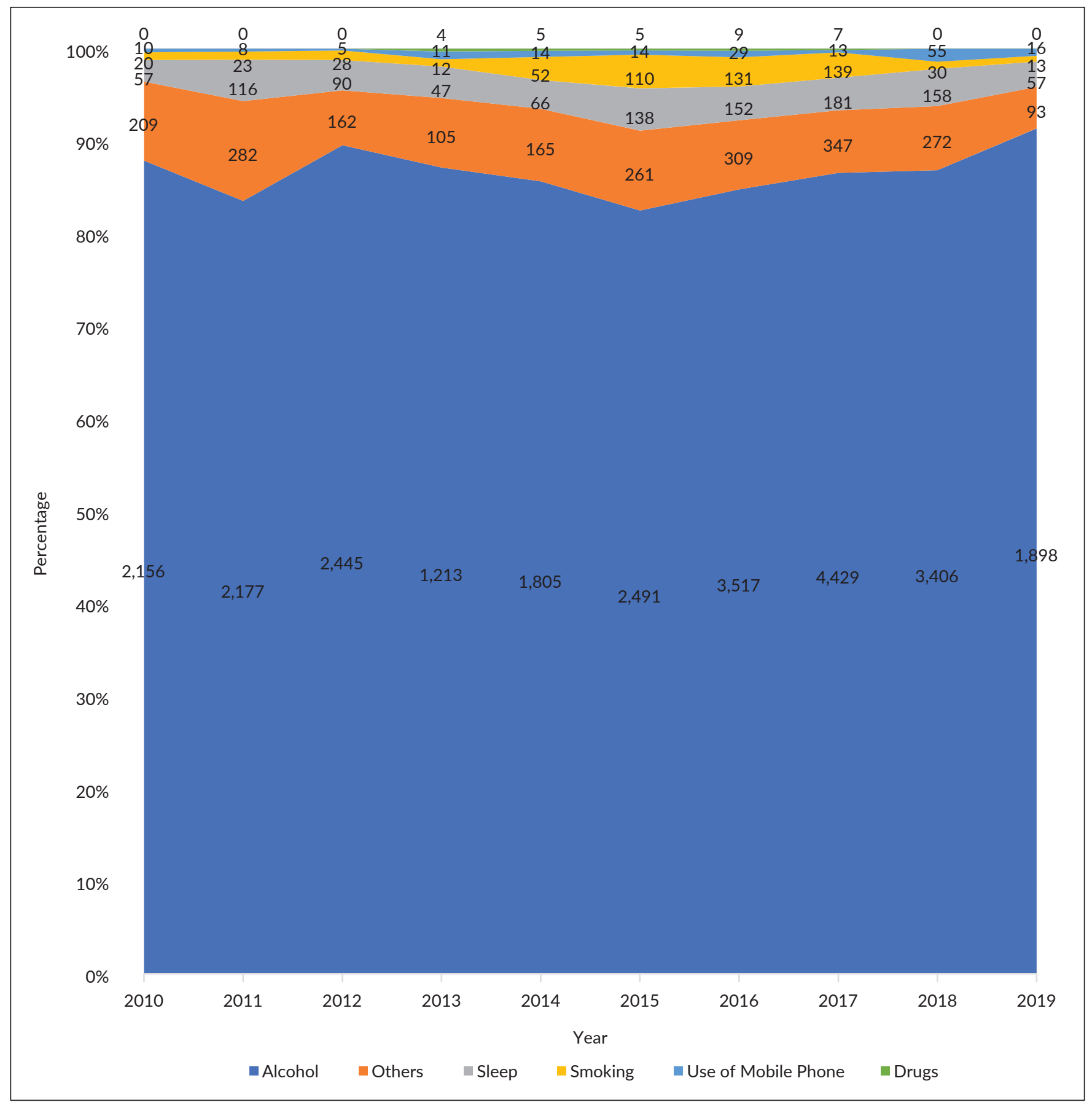

Figure 9. Distribution of contributing risk factors for TVC patients from the year 2010 to 2019.

Throughout the years, the number of ER deaths remained proportional to the total number of ER admissions at around $0.5 \%$ to $1 \%$. The majority (93.4\%) of TVC patients brought to the hospital were found to have an improved outcome (Figure 12). The same is true for inpatient outcomes where the number of deaths remained proportional to the total number of inpatient admissions at $2 \%$ to $3 \%$ every year. The highest outcome still comes from the "improved" category (85\%) (Figure 13).
Motorcycle use was significantly associated with ER outcomes $\left(\mathrm{X}^{2}[2,237882]=94.918, \mathrm{p}<0.0001\right.$. $)$ There was an association between use of motorcycles and unimproved outcomes. Other vehicle types were not significantly associated with ER outcomes (Table 3). The use of motorcycle was shown to be associated with the most injury types such as multiple injuries, abrasion, avulsion, and burn (Table 4).

Furthermore, alcohol use was significantly positively associated with multiple injuries, abrasion, avulsion, burn, 
open fracture, open wound, and amputation. Drugs were significantly positively associated with multiple injuries, burn, and open wound. Lastly, sleep was significantly positively associated with multiple injury, abrasion, avulsion, open fracture, and open wound (Table 5).

\section{DISCUSSION}

This study focused on the transport and vehicular crashes in the Philippines as recorded in the DOHONEISS database. The ONEISS database showed a steadily increasing trend of transport/vehicular collisions (TVC) in the Philippines accounting to $27 \%$ to $40 \%$ of the cases reported in the database from 2010 to 2019 . However, it must also be noted that there has been an increasing number of hospitals reporting to the ONEISS database. In this study, there is no comparable national database that can be used for comparison. However, it cannot be overlooked that TVC cases accounted for more than a third of the total hospital cases from the said years. Most of these accidents, however, were non-fatal. Data from the Land of Transportation Office showed that there was an average increase of $10.56 \%$ in the number of registered vehicles from 2017 to 2019.5 $\mathrm{Lu}(2016)^{6}$ associated the increase in car registrations and road congestion to a higher risk for road traffic accidents. The findings of this study are similar to India wherein an observed trend in increasing road traffic accidents from 2005 to 2015 was attributed to increasing vehicles on the

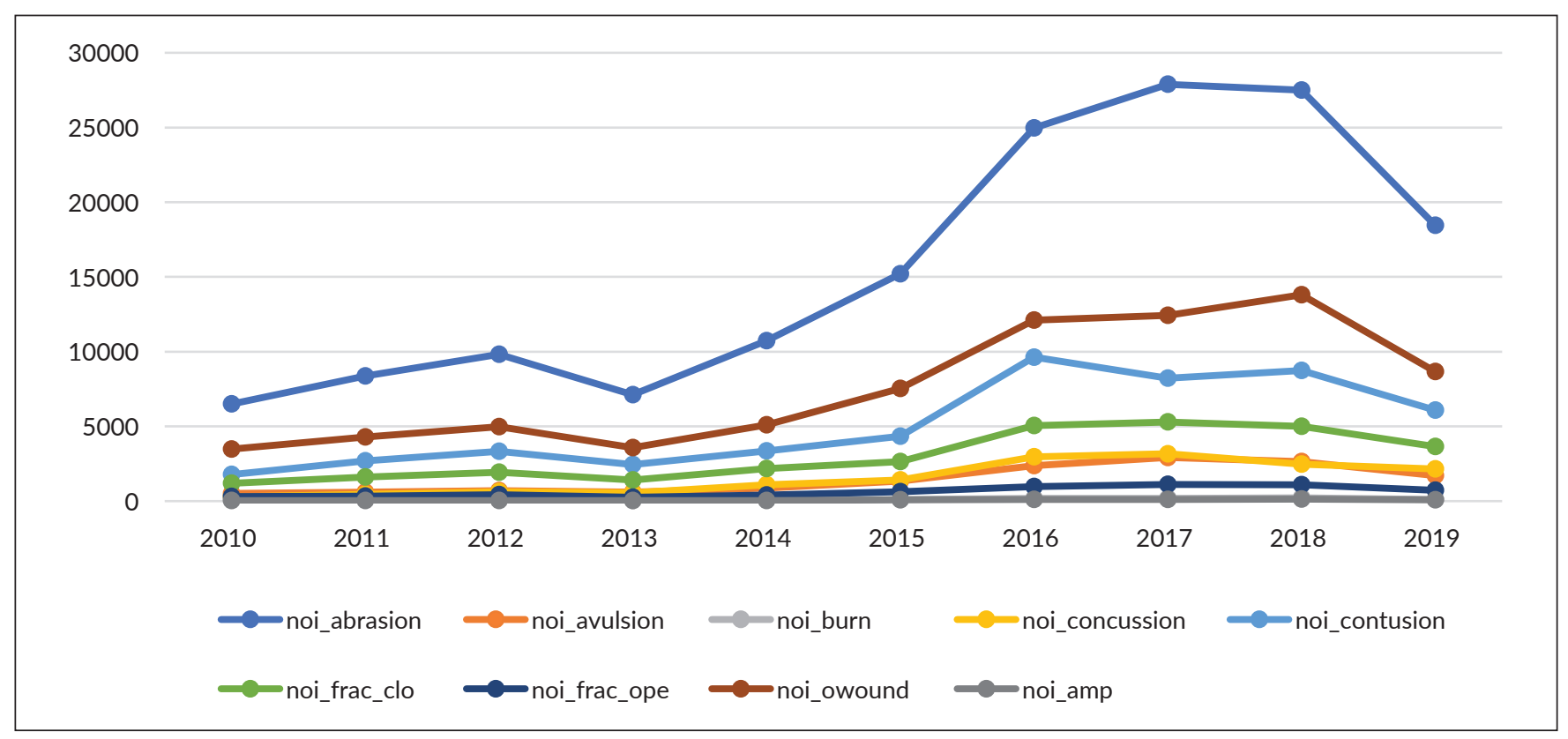

Figure 10. Distribution of nature of injury on TVC patients from the year 2010 to 2019.

Table 3. Test for association of outcomes for patients using motorcycle vehicle during road crash

\begin{tabular}{llcccc} 
& \multirow{2}{*}{ Motorcycle } & \multicolumn{3}{c}{ ER Outcome } & \multirow{2}{*}{ Total } \\
\cline { 3 - 5 } No & Count & Died & Improved & Unimproved & \\
& \% within ER Outcome & 673 & 94,669 & 5,518 & 100,860 \\
\hline \multirow{2}{*}{ Yes } & Count & $46.00 \%$ & $42.60 \%$ & $38.60 \%$ & $42.40 \%$ \\
\hline \multirow{2}{*}{ Total } & \% within ER Outcome & $54.00 \%$ & $57.40 \%$ & $61.40 \%$ & $57.60 \%$ \\
& Count & 1,463 & 222,137 & 14,282 & 237,882 \\
& \% within ER Outcome & $100.00 \%$ & $100.00 \%$ & $100.00 \%$ & $100.00 \%$ \\
\hline
\end{tabular}

Table 4. Test of association of motorcycle and injury $(N=290,169)$

\begin{tabular}{lccl}
\multicolumn{1}{c}{ Type of Injuries } & Pearson Chi-Square & p-value & Interpretation \\
Multiple Injuries & 2536.717 & $<0.0001$ & Highly significant association \\
Abrasion & 3848.465 & $<0.0001$ & Highly significant association \\
Avulsion & 326.443 & $<0.0001$ & Highly significant association \\
Burn & 92.197 & $<0.0001$ & Highly significant association \\
\hline
\end{tabular}




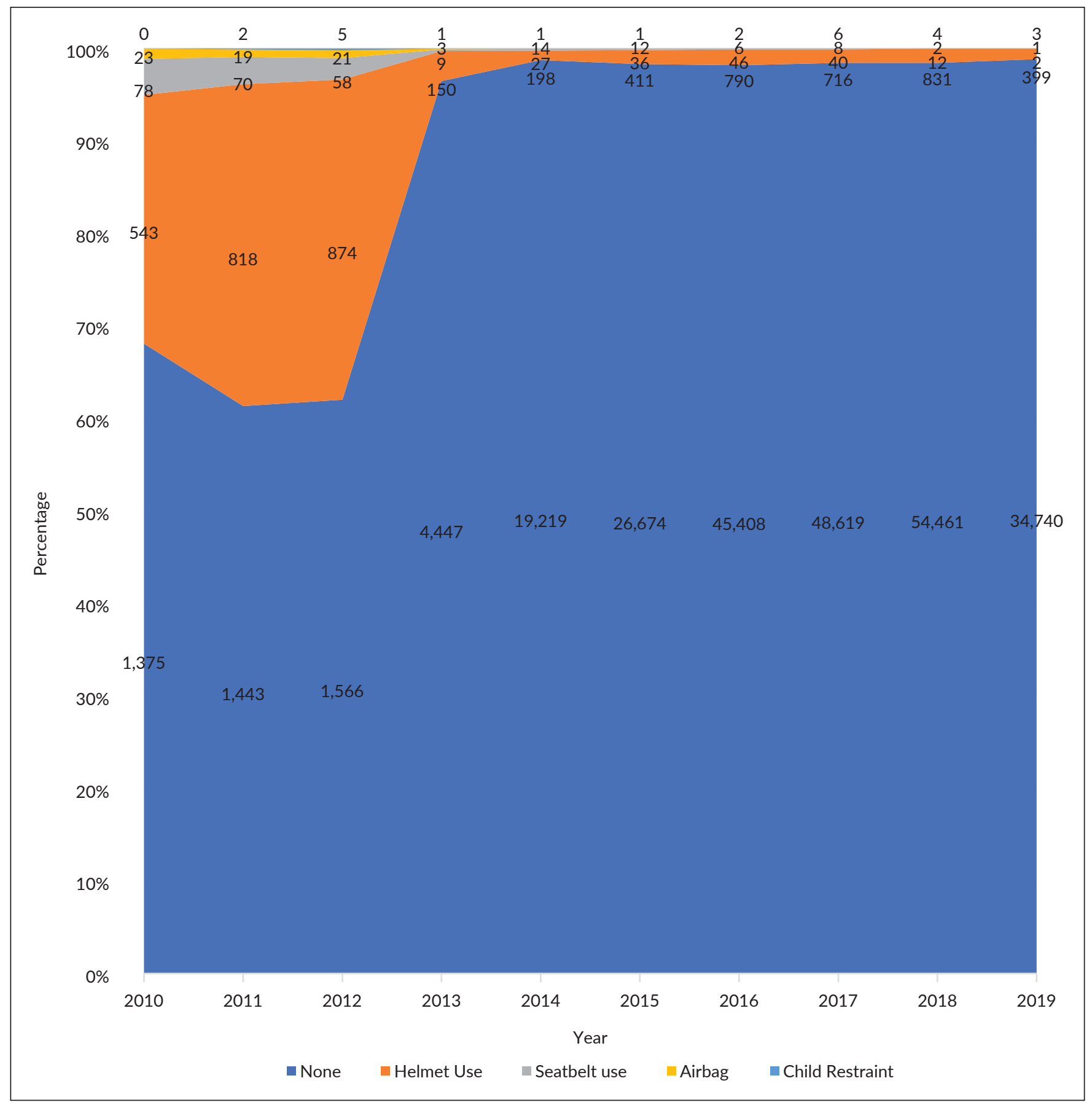

Figure 11. Distribution of TVC patients on the usage of safety gadgets in vehicles from the year 2010 to 2019.

road. ${ }^{7}$ Moreover, studies have also associated road accidents with sociodemographic characteristics (mean age of $32.3 \pm$ 18.5 years, males, single), helmet use, time of the day (fatal accidents at midnights), and behaviors, ${ }^{8-12}$ which were the main variables in this study.

The study showed that most cases of TVC occurred among individuals aged 0 to 30 years, with a peak at 20 years. This finding is similar to the study done in Rwanda wherein majority of victims were aged 20 to 45 years, and in New Delhi wherein $47.4 \%$ of road traffic injury patients were aged 16 to 30 years. ${ }^{13,14}$ This may be attributed to the fact that younger people are more at risk for engaging in risky behaviors such as speeding, drifting, one-wheeling competitions, rash driving, reckless and aggressive driving, impulsivity, and drunk driving, ${ }^{11}$ while older adults are more experienced and cautious. ${ }^{15,16}$

The study showed that males $(72.5 \%)$ were more likely to be involved in road crash compared to females (27.5\%). 


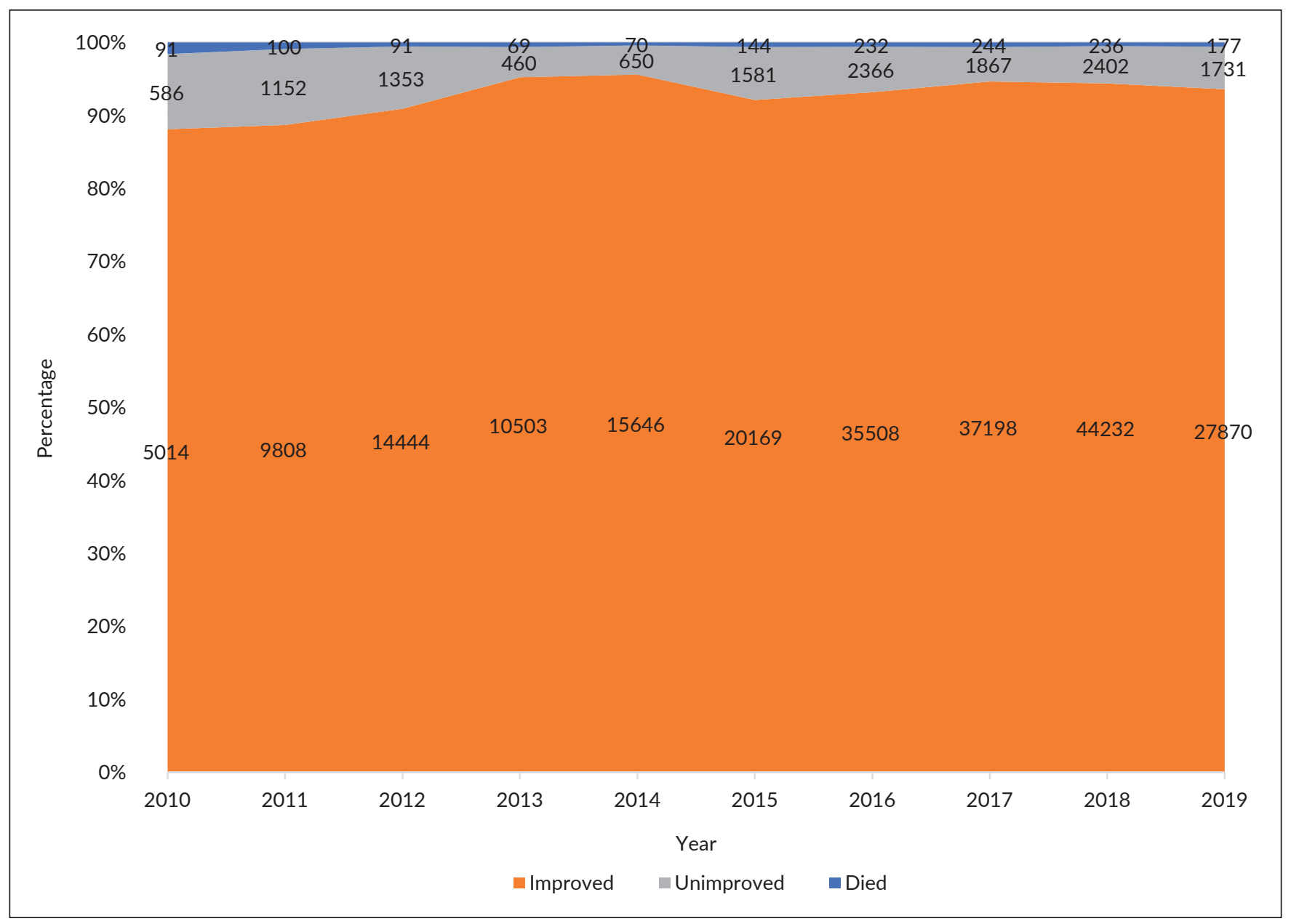

Figure 12. Distribution of ER outcomes from the year 2010 to 2019.

Table 5. Chi-square test results for risk factors and injuries sustained

\begin{tabular}{llccl}
\hline Risk Factors to Injuries & Associated Injuries & Pearson Chi-Square & p-value & Interpretation \\
\hline Alcohol Intoxication & Multiple Injury & 3160.946 & $<0.0001$ & Highly significant association \\
& Abrasion & 1613.987 & $<0.0001$ & Highly significant association \\
& Avulsion & 661.185 & $<0.0001$ & Highly significant association \\
& Burn & 17.371 & 0.0001 & Highly significant association \\
& Concussion & 81.702 & $<0.0001$ & Highly significant association \\
& Contusion & 314.418 & $<0.0001$ & Highly significant association \\
& Closed fracture & 159.83 & $<0.0001$ & Highly significant association \\
Open fracture & 44.834 & $<0.0001$ & Highly significant association \\
& Open wound & 3404.56 & $<0.0001$ & Highly significant association \\
& Amputation & 11.29 & 0.0001 & Highly significant association \\
\hline Drug Use & Multiple Injury & 6.907 & 0.01 & Highly significant association \\
& Burn & 5.918 & 0.01 & Highly significant association \\
& Open wound & 3.988 & 0.05 & Highly significant association \\
\hline Sleepiness & Multiple Injury & 96.335 & $<0.0001$ & Highly significant association \\
& Abrasion & 58.451 & $<0.0001$ & Highly significant association \\
& Avulsion & 7.827 & 0.005 & Highly significant association \\
& Contusion & 9.317 & $<0.001$ & Highly significant association \\
& Closed fracture & 9.812 & 0.06672 & Highly significant association \\
& Open fracture & 13.027 & 0.00031 & Highly significant association \\
& Open wound & 69.816 & $<0.0001$ & Highly significant association \\
\hline
\end{tabular}




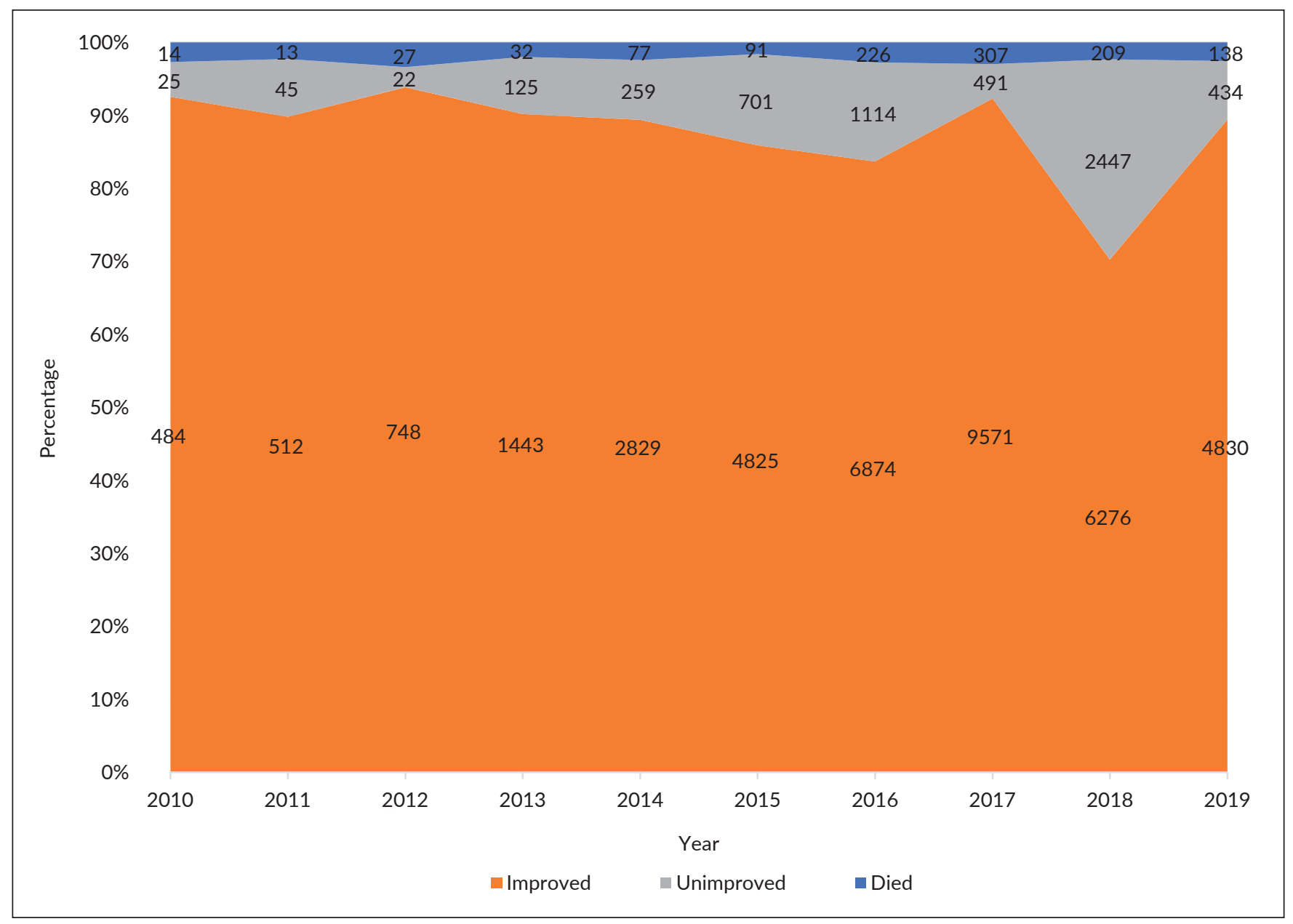

Figure 13. Distribution of in-patient outcomes from the year 2010 to 2019.

In another study, males were three times more likely to die as compared to females (Ding et al., 2016). A study on sex differences in road crash severity in Iran showed that injury severity for males increases due to behaviors such as violating rules, over speeding, and unnecessary haste and distraction. Meanwhile, severity of injury for female drivers increases due to lack of driving experience, loss of control and vehicle mechanical defect. The results of the study also showed that more victims were single (62.0\%). This is similar to studies in Ghana and Iraq where more than half $(63 \%$ and $56 \%$, respectively) of the victims were single. ${ }^{17,18}$ This may be attributed to the fact that single drivers tend to engage in risky road behaviors because they do not have children and spouses to support. ${ }^{9}$

The most vulnerable road users are motorcyclists, bicyclists, and pedestrians. ${ }^{3}$ This also supports the findings of this study that motorcyclists and pedestrians compose of majority of patients brought to the hospital each year: $53 \%$ to $62 \%$ for motorcycles and $9 \%$ to $14 \%$ for pedestrians. Similarly, in a study in Qatar, most victims of fatal road crash were drivers and pedestrians. ${ }^{19}$
In general, this study showed that risk factors such as alcohol, drugs, and fatigue are associated with injuries sustained during motorcycle injuries $(p<0.05)$ and that $8.9 \%$ of the patients reported in the ONEISS were confirmed to have consumed alcohol prior to the accident. Another study showed that $40.7 \%(n=749)$ of the road traffic accident victims had consumed alcohol prior to the accident and $38.1 \%$ consumed at least one psychoactive drug with alcohol. ${ }^{20}$ More so, in Thailand, the prevalence of drunk driving has increased from $36.6 \%$ in 2007 to $57.7 \%$ in $2017 .^{21}$ The results of this study showed that alcohol was associated with multiple injury, abrasions, avulsion, burn, open fracture, open wound and amputation, which may be attributed to impaired cognitive performance when drunk.

This study showed an alarmingly low usage of important safety equipment such as airbags, helmet, car seat, and seatbelt. If there is no air bag in the vehicle, the issue can be related with factories. However, in this study, the non-use of seatbelts, however, is more attributed to the drivers and passengers. Safety equipment and gadgets are important in preventing the risk for severe injuries. In another study, 
pedestrians and motorcyclists who generally lack protective equipment were found to sustain severe injuries much more than car riders. ${ }^{22}$ Yet another study showed that lack of protective equipment such as helmet and seatbelt could result in serious accidents. ${ }^{23}$ Safety equipment are introduced to protect the occupants from trauma during vehicle crashes. Airbags, for example, were found to be effective in reducing the risk of death and injury. ${ }^{24}$ Meanwhile, a meta-analysis done by Olivier and Creighton (2017) ${ }^{25}$ found that wearing a helmet when riding a bicycle reduces the odds of head injury, serious head injury, facial injury, and fatal head injury. The reduction was greater for serious or fatal head injury. ${ }^{25}$ A study in Brazil found that helmet use in motorcycle crash reduces occurrence of head trauma by about $76 \%$ and referral for hospitalization or death by $26 \% .^{26}$

The commonly reported activity that caused traffic vehicular crash was leisure. This is similar to a study in Spain where the probability of serious accidents was higher when the type of activity was leisure related. ${ }^{23}$ Leisure activity more often happens during the weekends. Also, younger drivers tend to be more active during their leisure time, contributing to the higher number of cases of road crash during leisure activity. ${ }^{27}$

Data from the ONEISS showed that, generally, fatal crashes, serious injuries, and minor injuries happen at night, with 6:00 pm as the peak and 5:00 am as the trough. This finding is similar to a study done by Ghandour et al. $(2020)^{28}$ wherein high fatality of road crash happens at $3 \mathrm{am}$. Fatality and severity of road crash during this time is associated with driver's fatigue, sleepiness, reduced visibility at night, non-lit roads, and alcohol consumption. ${ }^{28}$ Also, increased accidents at night rush hours may be attributed to congested roads, high levels of stress, fatigue, reduced visibility at night or combination of these factors. ${ }^{29}$

Ideally, all road crash victims should be brought to the post-treatment facility via an ambulance to ensure proper handling of victims. However, the results of this study showed that ambulance usage was lower than private vehicle usage. A low utilization of ambulances was also observed in India wherein an ambulance was only used by $23.30 \%$ of the RTA victims as compared to private vehicles (46.92\%). ${ }^{30}$ Ambulances may be limited in number and/ or the country may lack regulated ambulance system. ${ }^{31}$ It is important for the Philippines to have a concrete emergency medical service with ambulance transport as an integral part. It was found that victims transported using ambulance were more likely to exhibit 14 times severity of injuries compared to those who were transferred using other modes of transportation to health facility. ${ }^{32}$

Most of the patients had minor injuries, and the most common injuries sustained by the patients recorded in the ONEISS database were abrasions, open wounds, contusions and closed fractures. These results are similar to a study in Tanzania and Guinea wherein the most sustained injury were soft tissue injuries and fractures..$^{33,34}$
Vehicle type was also associated with injuries sustained by the victims. Multiple injury was associated with motorcycles. Woyessa et al. $(2020)^{35}$ found that majority of road crash victims had multiple injuries. The most frequent injured body parts were the head and chest. Meanwhile, other injuries observed for road traffic crash victims were external injuries and bone fractures. Delamou et al. $(2020)^{10}$ also claimed that motorcyclist in road crashes are 4 times more likely to have two or more injuries compared to another victim type. In this study in the Philippines, motorcycle use was also associated with several injuries including abrasions, burns, open wounds and amputation. This may be due to less protection gears by motorcycle riders. ${ }^{36}$ Motorcycles are also smaller, lighter and lacks structural support unlike other vehicles. ${ }^{37}$

Motorcycles are associated with fatal injuries as well, especially when accidents involve collisions with heavy vehicles. This is attributed to shared lanes of motorcycles and other vehicles in the road. Thus, exclusive motorcycle lanes could lessen the risk for fatal injuries. ${ }^{11}$ Most road systems in the Philippines do not have motorcycle lanes. Thus, it is important for the government to allocate exclusive spaces for motorcycles and bicycles. Despite these risks, motorcycles are still favored in low- to middle-income countries because these vehicles are inexpensive, cheaper to maintain, and it can be mobilized easily especially in roadways with heavy traffic. ${ }^{38}$ In the Philippines, there was an average increase of $10.34 \%$ in the new registrations of motorcycles/tricycles from 2017 to 2019.5

In this study, there was low seatbelt compliance and low usage of air bags. Kim et al. (2019) claimed that seatbelts can reduce the risk for traumatic brain injuries by $52 \%$, and that airbags does the same with fatal head injuries by $30 \%{ }^{39}$ The Philippines has a seatbelt law governed by RA 8750 ; however, the country currently does not have legislation requiring airbags for vehicles.

Despite the need for standardized emergency services, this study showed that the outcome of patients brought to emergency room and/or admitted generally improved. Although ER improvement outcomes are much higher than inpatient improved outcomes, this may be attributed to minor injuries sustained by patients brought to the ER. Those who were discharged after emergency consult were those deemed to have minor injuries such as scratches or slight confusion..$^{33}$ This data can imply that those with minor injuries who were discharged were noted as improved and explains why the ER had better outcomes compared to inpatient admissions.

In terms of vehicle association and outcomes, motorcycle was significantly associated with unimproved outcomes. This may be due to the high vulnerability of these road users due to non-use of protective gadgets and speeding on the road. In a study in Pakistan, severe injuries were attributed to poor usage of helmets and speeding. ${ }^{11}$ 
Lu (2016) ${ }^{6}$ in a study in Philippines and Ashraf et al. $(2019)^{40}$ in South Korea both found that the increasing car registrations could also be a contributing factor for the increased road accidents due to road congestion. It is also evident that there are more private vehicles registered than vehicles for hire. ${ }^{41,42}$ This may be attributed to the poor mass transportation in the Philippines, thereby more vehicles travelling the roads. This forces roadways to accommodate more than their allotted vehicle capacity. For instance, data in 2015 showed that overall trips in Metro Manila were comprised of $32 \%$ private vehicles while public buses that can accommodate 60 passengers only accounted to $14 \%$. With this data, we found that Epifanio de los Santos Avenue (EDSA) accommodates 300,000 vehicles, which is almost twice its 160,000 -vehicle capacity. ${ }^{43}$ This leads to congestion and a higher risk of accidents on the road. However, the increasing vehicle registration every year currently does not have corollary legislations.

The latest estimates in road crashes in the Philippines were in 2016. Reported fatalities in the country were 10,012. However, the WHO estimated this to be underreported and that the approximated fatalities due to road crashes in 2016 was 12,690 . The estimated non-fatal injuries in the country for the same year appeared to be $190,350 .{ }^{44}$

Road crashes burden the victims and the nation as a whole. Data from 2016 showed that $77 \%$ of road crash fatalities were within the economically-productive age groups (15 to 64 years old) with more males affected than females (3:1 ratio). Road crash accidents cause 635 life years lost due to disability from road crash injuries per 100,000 population of Filipinos affected. More so, the total cost of fatalities and serious injuries in the Philippines amounted to be $\$ 12,410$ million which in turn is a $4.1 \%$ loss in the country's GDP. ${ }^{44}$ Data in Metro Manila showed increasing trend in road crashes from 2005 (65,111 cases) to 2019 (121,771 cases) (MMDA, 2019). ${ }^{45}$ At present, national data on the total road crashes in the Philippines is not available; nevertheless, it cannot be overlooked that data from both MMARAS and this study in the Philippines showed an increasing trend in accidents and hospital admissions. More specifically, the current study showed a total of 296,760 TVC cases over the 10-year study period from 2010 to 2019 with an average increase of $25.58 \%$ per year. The road crash database in the Philippines is highly centered in the country's National Capital Region, as reported by the Metro Manila Development Authority (MMDA). Moreover, this study in the Philippines is highly centered within hospital data reporting to the Department of Health's ONEISS database. Therefore, there is a chance of underreporting the total number of road crashes in the Philippines.

The behaviors of road users were found to be also contributory factor to road crashes, with most of the behaviors found to be underreported in the ONEISS database. This crash database is important since an increasing number of road traffic crashes is observed globally. This database serves as the primary data source for road safety research. Moreover, good quality data is the backbone for monitoring the progress and effects of road traffic injury prevention measures. Chang et al. $(2020)^{2}$ have reported that the common problems concerning documentation in road traffic crashes are absence of regular data, underreporting, low specificity, distorted cause spectrum of road traffic injury, inconsistency, inaccessibility, and delay of data release. Thus, this calls for better data collection and reporting of the concerned hospitals that submit data to ONEISS because the latter is the basis for policymaking. This also shows the need for an integrated national road traffic accident reporting system. It is important that these databases are accurate to identify and solve the problems in relation to road safety.

\section{CONCLUSION}

An increasing trend in-patient admissions due to TVC was found in this study, mostly involving the productive age groups and young children ( 0 to 30 years old), drivers (45.6\%), males (72.5\%), vulnerable road users such as motorcyclists (53\% to $62 \%)$ and pedestrians (9\% to $14 \%$ ). The nature of injuries sustained by the patients were abrasions, open wounds, contusion, and closed fractures. Risk factors such as alcohol, sleep and use of drugs were found to be associated with nature of injuries $(p<0.05)$. Motorcycles were also the most involved vehicle type in TVC cases.

This study generally shows that the Philippines is experiencing rise in the cases of transport and vehicular crashes, more specifically, with motorcycles having the most TVC victims and being associated with most injuries and negative/unimproved outcome due to the lack of protective equipment for both the driver and passengers. Pedestrians are also victims of these crashes. This is alarming because both of these road users are considered the most vulnerable when it comes to crashes in the road.

Mortality and injuries from traffic and vehicular accidents can be reduced by instilling safety behavior and responsible driving/travelling to road users, proper and stronger implementation of the current policies on road safety, better road infrastructure for the safety of vulnerable road users, and systematic post-crash response of local government and/or hospitals concerned.

The use of national registries should be carried out such as the ONEISS surveillance system in the Philippines. However, there is still a need to increase the number of hospitals reporting to the database in order to capture a more accurate data on road crashes in the country. Comparable national databases should also be established by the transport sector as well as the traffic monitoring office as a complement to the ONEISS which is a health injury database.

\section{Acknowledgment}

Acknowledgment is cited for the Department of Surgery, PGH, UP Manila for access to their ISIS database. 


\section{Statement of Authorship}

All authors contributed in the conceptualization of work; acquisition and analysis of data; drafting and revising; and final approval of the version to be published.

\section{Author Disclosure}

All authors declared no conflicts of interest.

\section{Funding Source}

This project was funded by the Department of Health under its program on Advancing Evidence-Assisted Decisions with Health Policy and Systems Research (AHEAD-HPSR) through the Philippine Council for Health and Research Development, and in coordination with the National Institutes of Health, University of the Philippines Manila.

\section{REFERENCES}

1. World Health Organization. Road traffic injuries [Internet]. Geneva: World Health Organization; c2021 [updated 2020 Feb 7; cited 2021 Apr 21]. Available from https://www.who.int/news-room/fact-sheets/ detail/road-traffic-injuries

2. Chang FR, Huang HL, Schwebel DC, Chan AH, Hu GQ. Global road traffic injury statistics: Challenges, mechanisms and solutions. Chin J Traumatol. 2020 Aug; 23(4):216-8.

3. World Health Organization. Global Status Report on Road Safety 2018 [Internet]. Geneva: World Health Organization; 2018 [cited 2021 Apr 27]. Available from: https://www.who.int/publications/i/ item/9789241565684

4. Lam HY, Rivera AS, Macalino JU, Quebral JD, Cheng KJ, Miguel RTD. Estimating the social and economic burden of road traffic injuries in the Philippines. Acta Med Philipp. 2018 Sep; 52(5):423-28.

5. Land Transportation Office. Annual Report 2019 [Internet]. 2020 Jan 27 [cited $2021 \mathrm{Apr}$ ]. Available from: https://lto.gov.ph/transparencyseal/annual-reports/file/908-annual-report-2019.html

6. Lu SF. 530 Road crashes in Metro Manila: overview of road safety. Inj Prev. 2016; 22(Suppl 2):A191.

7. Gebretensay FB, Juremalani J. Road traffic accident analysis and prediction model: a case study of Vadodara City. Int Res J Eng Technol. 2018 Jan; 5(1):191-6.

8. Sadeghi-Bazargani H, Samadirad B, Hosseinpour-Feizi H. Epidemiology of traffic fatalities among motorcycle users in East Azerbaijan, Iran. Biomed Res Int. 2018 Aug 19; 2018:6971904.

9. Teye-Kwadjo E. Risky driving behaviour in urban Ghana: the contributions of fatalistic beliefs, risk perception, and risk-taking attitude. Int J Health Promot Educ. 2016 May; 57(5):256-73.

10. Delamou A, Karifa K, Camara BS, Kolie D, Grovogui FM, El Ayadi $\mathrm{AM}$, et al. Motorcycle accidents and their outcomes amongst victims admitted to health facilities in Guinea: a cross-sectional study. Adv Prev Med. 2020 Jun; 2020:1506148.

11. Pervez A, Lee J, Huang H. Identifying factors contributing to the motorcycle crash severity in Pakistan. J Adv Transport. 2021 Feb 28; 2021:6636130.

12. Chaichan S, Asawalertsaeng T, Veerapongtongchai P, Chattakul P, Khamsai S, Pongkulkiat P, et al. Are full-face helmets the most effective in preventing head and neck injury in motorcycle accidents? A meta-analysis. Prev Med Rep. 2020 Sep; 19:1011128.

13. Patel A, Krebs E, Andrade L, Rulisa S, Vissoci JRN, Staton CA. The epidemiology of road traffic injury hotspots in Kigali, Rwanda from police data. BMC Public Health. 2016 Aug; 16:697.

14. Misra P, Majumdar A, Misra MC, Kant S, Gupta SK, Gupta A, Kumar S. Epidemiological study of patients of road traffic injuries attending emergency department of a trauma center in New Delhi. Indian J Crit Care Med. 2017 Oct; 21(10):678-683.
15. Flores GM, Gotohio MP, Paras NG, Seva RR. Analysis of motorcycle accidents based on environmental and personal factors. Manila, Metro Manila, Philippines. In: Proceedings of the 2nd International Conference on Industrial Engineering and Operations Management; 2011 Jan 22-24; Kuala Lumpur, MY. Sydney: IEOM Research Solutions Pty Ltd; 2011. p. 820-5.

16. Adebisi A, Ma J, Masaki J, Sobanjo J. Age-related differences in motor-vehicle crash severity in California. Saf. 2019 Aug 7; 5(3):48.

17. Konlan KD, Doat AR, Mohammed I, Amoah RM, Saah JA, Konlan $\mathrm{KD}$, et al. Prevalence and pattern of road traffic accidents among commercial motorcyclists in the Central Tongu District, Ghana. Sci World J. 2020 Jun; 2020:9493718.

18. Flayyih SS, Hameed IH, Fakhir FD. Road traffic accident coming to Hillah Teaching Hospital: prospective and retrospective study. Research J Pharm and Tech. 2017 Nov; 10(11):1827-32.

19. Timmermans C, Alhajyaseen W, Al Mamun A, Wakjira T, Qasem M, Almallah M, et al. Analysis of road traffic crashes in the State of Qatar. Int J Inj Control Saf Promot. 2019 Sep; 26(3):242-50.

20. Papalimperi AH, Athanaselis SA, Mina AD, Papoutsis II, Spiliopoulou CA, Papadodima SA. Incidence of fatalities of road traffic accidents associated with alcohol consumption and the use of psychoactive drugs: A 7-year survey (2011-2017). Exp Ther Med. 2019 Sep; 18(3): 2299-306.

21. Vichitkunakorn P, Intusoma U, Assanangkornchai S. Binge Drinking and Drunk Driving Among Current Drinkers in Thailand: Analysis of Cigarette Smoking and Alcohol Drinking Behavior Surveys From 2007 to 2017. Asia Pac J Public Health. 2020 Nov 4: 1010539520971178.

22. Manouchehrifar M, Ghalandari R, Hatamabadi H. The impact of safety equipment on the road users of traffic accidents: a hospital based study. Trauma Mon. 2019 Feb; 24(1):e65580.

23. Febres JD, Mohamadi F, Mariscal MA, Herrera A, García-Herrero $\mathrm{S}$. The role of journey purpose in road traffic injuries: a Bayesian network approach. J Adv Transport. 2019 Dec; 2019:6031482.

24. O'Donovan S, van den Heuvel C, Baldock M, Byard R. Injuries, death and vehicle airbag deployment. Med Sci Law. 2020 Apr; 60(2):147-9.

25. Olivier J, Creighton P. Bicycle injuries and helmet use: a systematic review and meta-analysis. Int J Epidemiol. 2017 Feb; 46(1):278-92.

26. Souto RMCV, Corassa RB, Lima CM, Malta DC. Helmet use and injury severity among crashed motorcyclists in Brazilian state capitals: an analysis of the violence an accident survey 2017. Rev Bras Epidemiol. 2020; 23(Suppl 1):e200011.

27. Moller M, Sigurdardottir SB. The relationship between leisure time and driving style in two groups of male drivers. Transp Res. 2009 Nov; 12(6):462-9.

28. Ghandour A, Hammoud H, Al-Haji S. Analyzing factors associated with fatal road crashes: a machine learning approach. Int J Environ Res Public Health. 2020 Jun 9; 17(11):4111.

29. Cabrera-Arnau C, Prieto Curiel R, Bishop S. Uncovering the behaviour of road accidents in urban areas. R Soc Open Sci. 2020 Apr $15 ; 7: 191739$.

30. Urfi, Khalique N, Ahmad A, Ahmad ST. Post-crash emergency care: Availability and utilization pattern of existing facilities in Aligarh, Uttar Pradesh. J Family Med Prim Care. 2020 May 31; 9(5):2313-18.

31. Padlan MP, Mesa-Gaerlan FJ. Philippine Emergency Medical Services: A Medical Student's Perspective. Juntendo Medical Journal. 2018;64(4):295-8.

32. Gebresenbet RF, Aliyu AD. Injury severity level and associated factors among road traffic accidents victims attending emergency department of Tirunesh Beijing Hospital, Addis Ababa, Ethiopia: a cross sectional hospital-based study. PLoS One. 2019 Sep; 14(9):e0222793.

33. Kourouma K, Delamou A, Lamah L, Camara BS, Kolie D, Sidibé S, et al. Frequency, characteristics and hospital outcomes of road traffic accidents and their victims in Guinea: a three-year retrospective study from 2015 to 2017. BMC Public Health. 2019 Jul 31; 19(1):1022.

34. Chalya P, Mabula J, Dass R, Mbelenge N, Ngayomela I, Chandika A, et al. Injury characteristics and outcome of road traffic crash victims at Bugando Medical Centre in Northwestern Tanzania. J Trauma Manag Outcomes. 2012; 6:1 
35. Woyessa AH, Heyi WD, Ture NH, Moti BK. Patterns of road traffic accident, nature of related injuries, and post-crash outcome determinants in western Ethiopia - a hospital -based study. Afr J Emerg Med. 2021 Mar; 11(1):123-31.

36. Yousif MT, Sadullah AF, Kassim KA. A review of behavioural issues contribution to motorcycle safety. IATSS Res. 2020 Jul; 44(2):142-54.

37. Michon K. Motorcycle Accidents: An Overview. Berkeley (CA): $\mathrm{MH}$ Sub I, LLC dba Nolo; c2021 [cited 2021 Apr 23]. Available from: https://www.nolo.com/legal-encyclopedia/motorcycle-accidentsoverview-30329.html

38. Dos Santos WJ, Coêlho VMDS, Bonfim CVD, de Ceballos AGDC. Alcohol and risky behavior in traffic among motorcyclists involved in accidents in a city in northeastern Brazil. Traffic Inj Prev. 2019; 20(3):233-7.

39. Kim JM, Kim SC, Lee KH, Kim HJ, Kim H, Lee SW, Na DS, Park JS. Preventive effects of seat belts on traumatic brain injury in motor vehicle collisions classified by crash severities and collision directions. Eur J Trauma Emerg Surg. 2019 Feb 23.

40. Ashraf I, Hur S, Shafiq M, Park Y. Catastrophic factors involved in road accidents: Underlying causes and descriptive analysis. PLoS One. 2019 Oct 9; 14(10):e0223473.
41. Land Transportation Office. Annual Report 2012. 2012 [cited 2021 Jul]. Available from: https://tto.gov.ph/transparency-seal/annualreports/file/14-annual-report-2012.html

42. Land Transportation Office. Annual Report 2019. 2019 [cited 2021 Jul]. Available from: https://lto.gov.ph/transparency-seal/annualreports/file/908-annual-report-2019.html

43. Francisco F. To solve Metro Manila traffic: Move more people, not cars [Internet]. Manila: Rappler; c2021 [updated 2015 Oct 02; cited 2021 Jun]. Available from: https://www.rappler.com/nation/metro-manilatraffic-move-people

44. Global Road Safety Facility [Internet]. Washington: The Global Road Safety Facility; c2021 [cited 2021 Jul]. Road Safety in Philippines; [about 5 screens]. Available from: https://www.roadsafetyfacility.org/ country/philippines

45. Metro Manila Development Authority (MMDA). MMARAS Annual Report 2019 [Internet]. 2019 [cited 2021 Jul]. Available from: https://mmda.gov.ph/images/Home/FOI/MMARAS/MMARAS_ Annual_Report_2019.pdf 